\title{
The fertility impact of changes in the timing of childbearing in the developing world
}

John Bongaarts

Population Council

Follow this and additional works at: https://knowledgecommons.popcouncil.org/departments_sbsr-pgy

Part of the Demography, Population, and Ecology Commons, Family, Life Course, and Society Commons, and the International Public Health Commons How does access to this work benefit you? Let us know!

\section{Recommended Citation}

Bongaarts, John. 1999. "The fertility impact of changes in the timing of childbearing in the developing world," Policy Research Division Working Paper no. 120. New York: Population Council. Version of record: https://doi.org/10.1080/00324720308088 


\section{The Fertility Impact of Changes in the Timing of Childbearing in the $D$ eveloping World}

John Bongaarts

1999 No. 120 


\title{
The Fertility Impact of Changes in the Timing of Childbearing in the Developing World
}

\author{
John Bongaarts
}

John Bongaarts is Vice President, Policy Research Division, Population Council, New York. 


\begin{abstract}
This study examines the role of tempo effects in the fertility declines of developing countries. These effects temporarily inflate the total fertility rate (relative to the actual fertility of cohorts of women) during periods when the age at childbearing declines, and they deflate it when childbearing is postponed. An analysis of data from the World Fertility Surveys and the Demographic and Health Surveys demonstrates that fertility trends observed in many developing countries are likely to be distorted by changes in the timing of childbearing. In most countries women are delaying childbearing, which implies that observed fertility is lower than it would have been without tempo changes. This pattern is most clearly documented in Taiwan, where accurate birth statistics from a vital registration system make it possible to estimate the tempo components of fertility annually from 1978 to 1993 . The small but unexpected rise in total fertility rates in Colombia in the early 1990 s is attributed to a decline in the negative tempo distortion that prevailed in the 1980s. Similar interruptions of ongoing fertility declines may occur in the future in other countries when existing negative tempo effects are removed.
\end{abstract}

This material may not be reproduced in any form without written permission from the author. 
Fertility in the developing world has declined sharply over the past three decades. According to recent United Nations estimates the total fertility rate (TFR) for the developing world remained close to 6.0 births per woman during the $1950 \mathrm{~s}$ and 1960s, but dropped steadily since then to reach 3.3 in 1990-95, and the projected value for 1995-2000 is 3.1 births per woman (United Nations 1996). Trends have differed widely among regions and countries, with some populations completing the transition to replacement fertility in record time (e.g., Hong Kong, Singapore, South Korea, Taiwan), while others (mostly in sub-Saharan Africa) have seen little change in reproductive behavior. Between 1960-65 and 1990-95 the largest fertility declines occurred in Asia (-52\%) and Latin America (-50\%) while the smallest declines occurred in sub-Saharan Africa (-7\%).

Although many analysts are familiar with these general fertility trends, relatively few are aware that the most widely used indicator for monitoring fertility trends - the total fertility rate — is a hypothetical measure that under certain circumstances can give distorted results. The TFR is defined as the average number of births a woman would have if she were to live through her reproductive years (ages 15-49) and bear children at each age at the rates observed in a particular year or period. It is a hypothetical measure because no real group of women has experienced or will necessarily experience these particular rates. Among the various flaws that have been identified in the substantial literature on the topic, perhaps the most important is the distortion in the TFR that results from changes in the timing of childbearing. These so-called tempo effects have been analyzed extensively by Ryder $(1964,1980,1983)$. A tempo effect manifests itself by temporarily inflating the TFR (relative to the actual fertility of cohorts of women) during periods when the age at childbearing declines for successive cohorts. The best-known example of this pattern occurred during the baby boom in the 1950s in the United States. The opposite effect is also important: when successive cohorts delay childbearing the TFR is temporarily depressed, as has happened in the US and a number of other developed countries since the mid1970s (Bongaarts and Feeney 1998; Bongaarts 1998). The observed TFR at a 
given point in time can therefore be seen as consisting of two distinct parts: 1) a "quantum" component, which equals the TFR that would have been observed in the absence of changes in the timing of births, and (2) a "tempo" component that is attributable to the advancing or delaying of births. The quantum component measures the true propensity to reproduce and the tempo effects-whether positive or negative- can be considered for many purposes to be an undesirable distortion of the observed TFR.

The objective of this study is to examine the role of tempo effects in the fertility declines of developing countries. Past studies of timing effects have concentrated on developed countries, where fertility has reached or is approaching the end of the demographic transition and where the existence of tempo effects is fairly well accepted. In contrast, tempo effects are usually ignored in the analysis of fertility trends in developing countries even though in theory there is no reason to expect them to be limited to the developed world. In fact, the presence of tempo effects is strongly suggested by the increases in the median ages at marriage and first birth measured in many countries with DHS surveys (Blanc and Rutenberg 1990; Singh and Samara 1996). As will be demonstrated below, substantial tempo distortions do indeed exist in many developing countries.

\section{MEASURING TEMPO CHANGES}

The first step in any analysis of tempo effects is the measurement of changes in the timing of childbearing. This turns out to be less simple than it might appear. In conventional usage the term childbearing tempo refers to the timing of births by age of mother (Pressat 1985:191). The most widely used indicator of timing is the mean age at childbearing (MAC) and this is in fact the main tempo measure used by Ryder. Over the course of a fertility transition the MAC usually declines. For example, in Taiwan the TFR and MAC trends from 1960 to 1990 were as follows (Republic of China 1991): 


\begin{tabular}{lcc} 
& TFR (bpw) & MAC (years) \\
\hline 1960 & 5.8 & 29.8 \\
1970 & 4.0 & 27.6 \\
1980 & 2.5 & 26.2 \\
1990 & 1.8 & 27.1 \\
\hline
\end{tabular}

Between 1960 and 1980 Taiwan's mean age at childbearing declined from 29.8 to 26.2 years, but during the 1980 s it turned up slightly to 27.1 years. To identify the forces influencing this trend it is useful to examine briefly the changes over time in the age pattern of fertility. Figure 1 presents the age-specific fertility rates of Taiwan over the course of the transition from 1960 to 1990 . Before 1980 the dominant change occurred among older age

Figure 1 Age-specific fertility rates: Taiwan, 1960-90

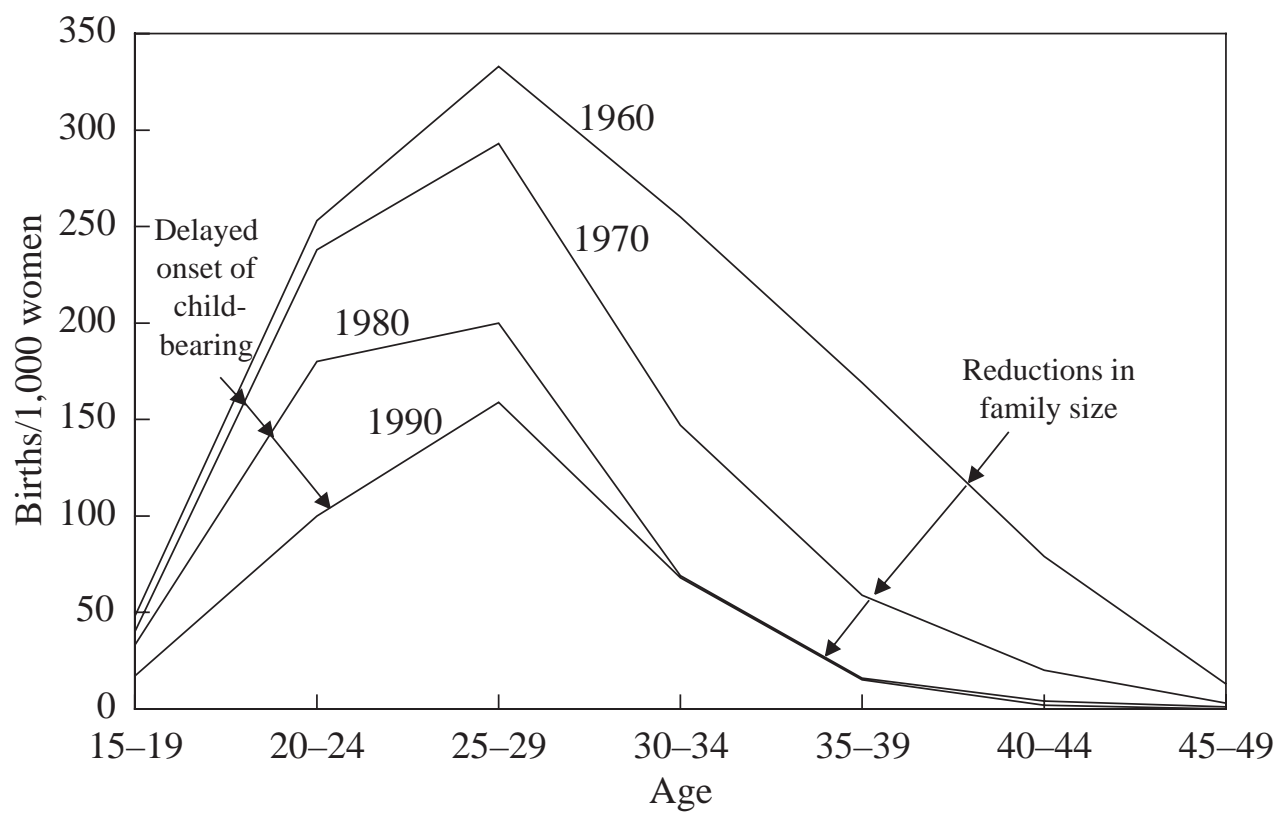

Source: Republic of China, 1990, 1991. 
groups, whose fertility declined sharply as women limited their family sizes by reducing higher-order births. Since the 1970s and increasingly in the 1980s fertility rates among younger women fell also, primarily as a result of a postponement of the onset of childbearing.

In general, the timing of the onset of childbearing in the younger age groups and the degree of family limitation in the older age groups are the two determinants of the mean age at childbearing. These factors, and hence the MAC, change in magnitude over time and differ among populations. In contemporary developing countries the mean age at childbearing ranges from 25 to 32 years (World Bank 1998). The estimates of MAC plotted for 160 populations in Figure 2 show a clear positive correlation with the TFR: populations with TFRs above 6 have MACs near 30 years while populations with TFRs of less than 2.5 have MACs around 27.5 years. This finding implies that the downward pressure on the MAC

Figure 2 Relationship between average age at childbearing and total fertility rate: Estimates for 160 developing countries, 1995-2000

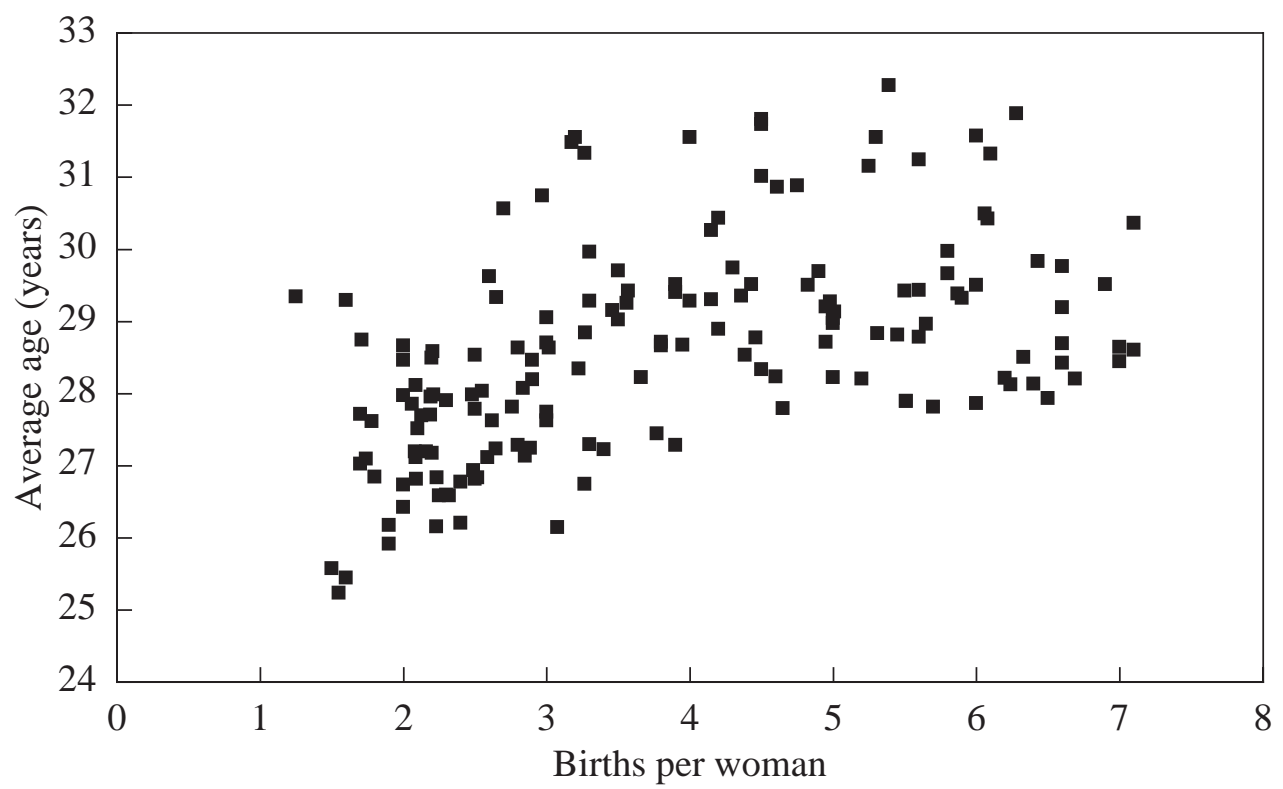

Source: World Bank 1998. 
exerted by declines in higher-order births is not fully offset by increases in the ages at births of different orders as countries move through their fertility transitions.

The mean age at childbearing is a useful indicator for a variety of purposes, but it is not suitable for the measurement of tempo distortions of the TFR (Bongaarts and Feeney 1998; Hobcraft 1996). The reasons for this can be demonstrated with a simple illustration. Figure 3 presents highly stylized patterns of childbearing at the beginning and end of two hypothetical fertility transitions. The pre-transitional situation is the same in Figures 3a and 3b: all women have exactly 6 births and each birth occurs at the same age for all women-the first at age 20 , the second at age 23 , and so on until the last at age 35 . The mean age at childbearing in this case is therefore 27.5 years. The transitions summarized in Figure 3 also have the same post-transitional TFR of 2, but they differ in their assumptions about the trend in the timing of births. In Figure $3 \mathrm{a}$ the timing of

Figure 3 Hypothetical childbearing patterns, with and without timing effects
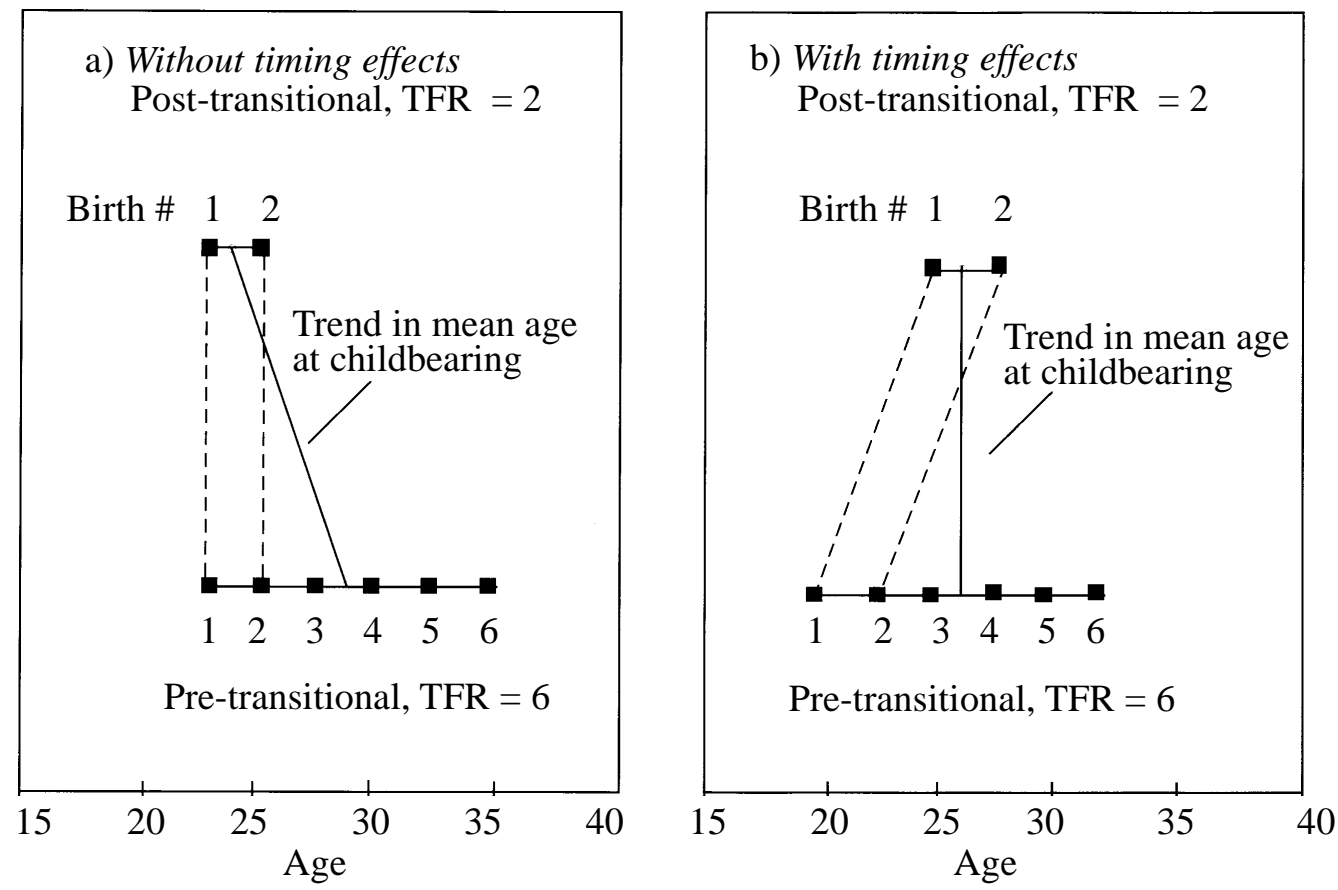
each birth is assumed to remain fixed over the course of the transition so that at its end the first birth still occurs at age 20 and the second at age 23. As a consequence, the mean age at childbearing declines by six years from 27.5 to 21.5 years over the course of this transition. By relying on the trend in the MAC one would conclude that a large tempo change had occurred in this situation, while in fact the timing of births has been fixed by assumption. The elimination of births of higher order leads to changes in the mean age at childbearing that do not accurately represent tempo effects of interest here.

Figure $3 \mathrm{~b}$ presents a very different situation. In this case the onset of childbearing is delayed by six years during the transition, and in the post-transitional setting the first birth occurs at age 26 and the second at age 29. The mean age at childbearing is now the same - 27.5 years — at the beginning and end of the transition. This finding might lead one to conclude that there have been no tempo changes. In fact, the timing of the first and second births was assumed to be delayed by a substantial period, but this effect on the MAC is offset by the elimination of higher-order births. Reliance on the trend in the mean age at childbearing in the two situations represented by Figures $3 \mathrm{a}$ and $3 \mathrm{~b}$ leads to erroneous conclusions about the size of the tempo effect. The mean age at childbearing is therefore not a useful indicator for investigating the fertility impact of changes in the tempo of fertility.

The solution to this problem is relatively simple: instead of focusing on the mean age of all births it is necessary to examine separately changes in the timing of births of different orders. An examination of trends in the mean ages at first and second births would have led to the correct conclusion in the above hypothetical illustrations: no tempo effects in Figure 3a and substantial effects in Figure $3 \mathrm{~b}$. Before turning to an analysis of observed tempo changes by birth order it is useful to examine briefly variations among populations in the sizes of the order components of the TFR. 


\section{BIRTH-ORDER COMPONENTS OF FERTILITY}

The birth-order components of a total fertility rate are defined here as the parts of the rate that are attributable to births of given orders. To illustrate, examine the components of the total fertility rate for a cohort of women (CTFR) who have reached the end of their reproductive years. The CTFR equals the average number of births these women have had during their lifetimes. The first-order component $\left(\mathrm{CTFR}_{1}\right)$ of cohort fertility is simply the average number of first births per woman, which equals the proportion of the cohort that has had a first birth during their lives; the second-order component $\left(\mathrm{CTFR}_{2}\right)$ is the average number of second births per woman, which equals the proportion that has had a second birth, and so forth. ${ }^{1}$ The sum of these components equals the CTFR ( $\Sigma$ CTFR $_{\mathrm{o}}$ ). Figure 4 presents the CTFR components for cohorts of women aged 45-49 in several countries with recent DHS surveys as well as the 1940 cohort of US women. The cohort total fertility rates in these countries range from 7.9 births per woman in Kenya to 2.7 for the US. Note that the CTFR is proportional to the area under the curves plotted in Figure 4. As expected, none of the birth-order components exceeds one, because women can have no more than one birth of any order, and the components decline as order rises, because no woman can have a birth of a given order without also having had a birth of the preceding order. The differences between countries in the birth-order components are largest for the higher orders and relatively modest for birth order 1 . This implies that reductions in the CTFR in most countries are primarily achieved by limiting higherorder births.

This component analysis of the fertility of cohorts can be repeated for period total fertility rates. The conventional TFR estimates fertility in a given period in terms of average numbers of births per woman and includes births of all orders. It is computationally straightforward to calculate a total fertility rate for any specific birth order. Instead of including births of all orders in the numerators 
Figure 4 Birth-order components of the completed total fertility rate of women aged 45-49 in selected countries

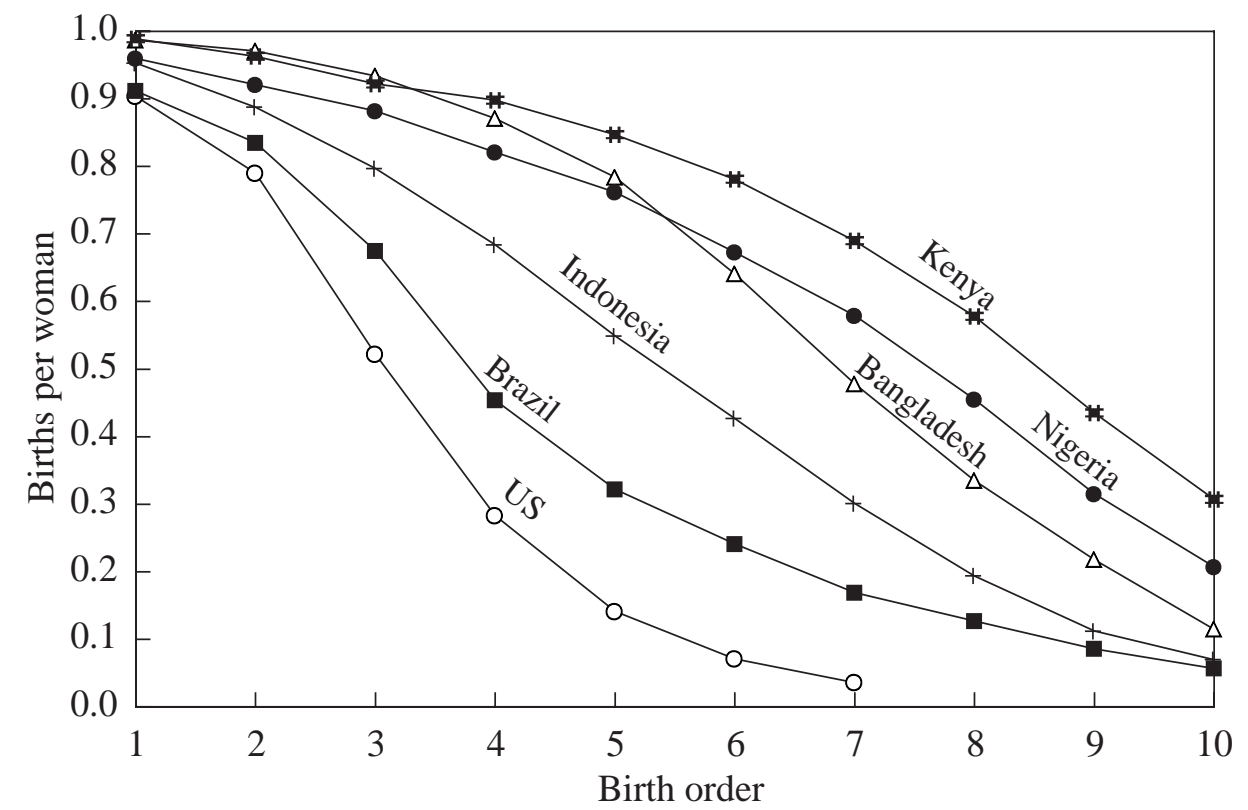

Source: DHS standard recode files.

of the age-specific fertility rates on which the TFR is based, only births of a single order are included and the same denominators are used. The results of such a calculation for each birth order o is a set of birth-order components TFR that when summed equal the TFR $(\text { TFR }=\Sigma \text { TFR })_{0}$. Estimates of the TFR components for the five-year period before the most recent DHS survey are provided in Figure 5 for the same populations as in Figure 4 and for the year 1975 in the US.

A comparison of the fertility component of cohorts (Figure 4) and periods (Figure 5) in the same countries reveals a surprising difference. The first-order components of cohort fertility $\left(\mathrm{CTFR}_{1}\right)$ exceed 0.9 births per woman in all six countries, which implies that more than 90 percent of women had at least one birth. In contrast, the period profiles presented in Figure 5 suggest that childlessness is much more common, because the first-order component of the total fertility rate, $\mathrm{TFR}_{1}$, is less than 0.87 in all these countries. For example, in Bangladesh 
Figure 5 Birth-order components of the period total fertility rate in selected countries

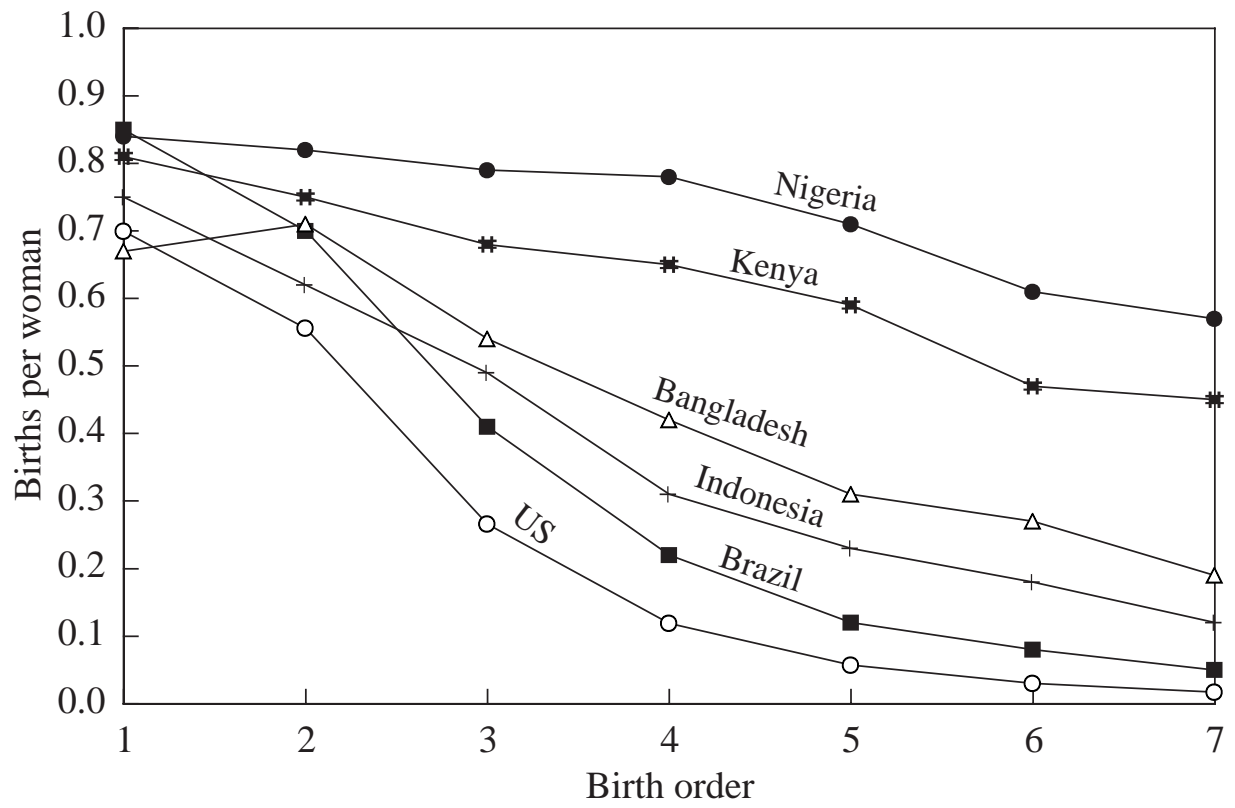

Source: DHS standard recode files.

TFR $_{1}$ equals 0.67 , which suggests that only 67 percent of all women will have a first birth and 33 percent will remain childless. While some decline over time might be expected, such a large proportion of childless women is highly unlikely to be found in Bangladesh or other traditional societies. There must be an alternative explanation for the unexpectedly small size of these first-order components of period fertility. As will be demonstrated below, the most likely cause is a tempo distortion.

\section{TEMPO DISTORTIONS OF TFR COMPONENTS}

To demonstrate the conditions under which tempo distortions can be expected to occur, and to identify the factors that determine their magnitude, it is again helpful to examine a set of simple illustrations as presented in Figure 6. In these hypothetical illustrations, every woman is assumed to have exactly one 
birth so that CTFR = 1 for all cohorts, and these births are assumed to take place at exactly the same age within each cohort. Figure 6a depicts the reference situation in which this age is set at exactly 20 years. Since there are no tempo effects, period fertility as measured by the TFR is also constant and equal to 1 birth per woman. Assume next that starting at time T successive cohorts delay childbearing so that the mean age at first birth rises linearly from 20 to 21 years over a tenyear period from $\mathrm{T}$ to $\mathrm{T}+10$ (see Figure $6 \mathrm{~b}$ ). In this case the TFR drops from 1 to 0.9 at time $\mathrm{T}$, remains at 0.9 from $\mathrm{T}$ to $\mathrm{T}+10$, and finally returns to 1 after time $\mathrm{T}$. In other words the TFR is distorted by 10 percent or 0.1 birth per woman during the interval $\mathrm{T}$ to $\mathrm{T}+10$. Conversely, as shown in Figure $6 \mathrm{c}$, if the mean age at first birth is assumed to decline linearly from 20 to 19 years over the same ten-year period, then the TFR rises from 1 to 1.1 at time $\mathrm{T}$, remains at 1.1 from $\mathrm{T}$ to $\mathrm{T}+10$, and returns to 1 birth per woman after $\mathrm{T}$.

Figure 6 Hypothetical illustrations of the fertility impact of changes in the mean age at childbearing

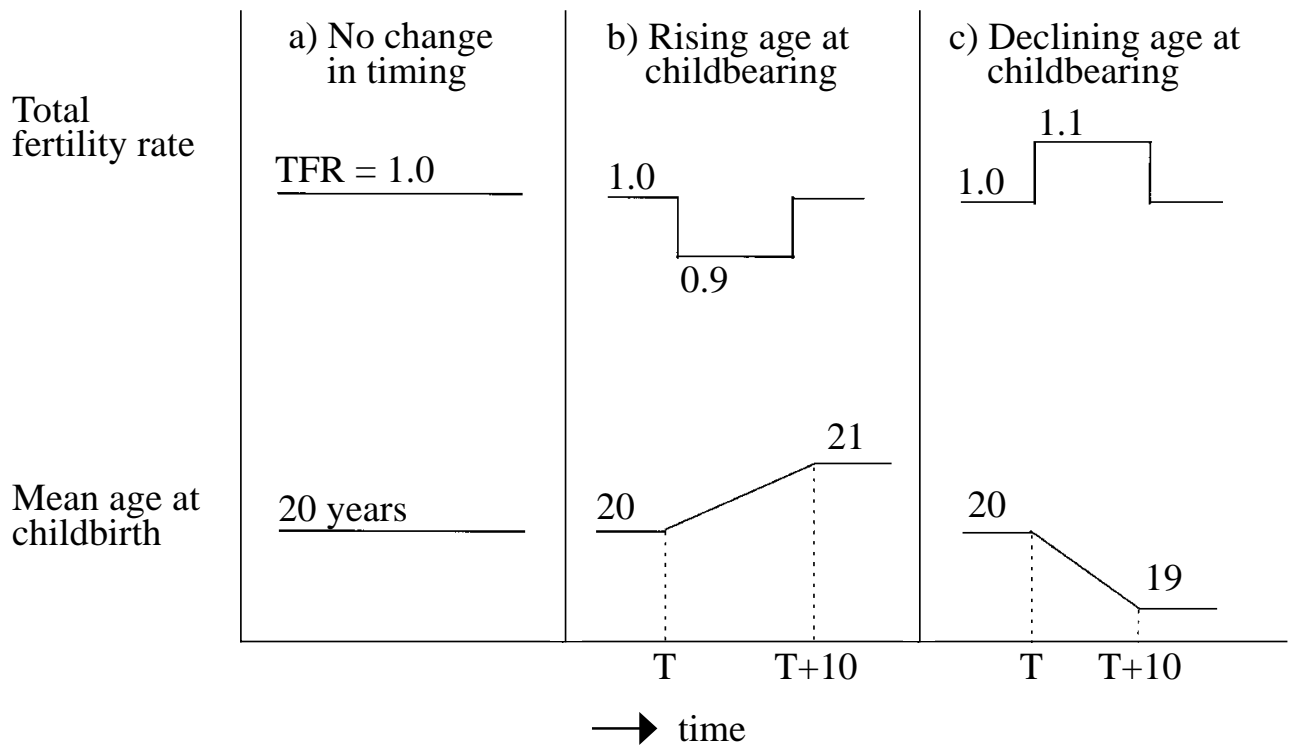


These tempo effects are caused by the fact that the number of births that occur between $\mathrm{T}$ and $\mathrm{T}+10$ in Figure $6 \mathrm{~b}$ is the same as the number that occurred between time $\mathrm{T}$ and $\mathrm{T}+9$ in Figure $6 \mathrm{a}$. In moving from situation a to situation $\mathrm{b}$, the births that took place at $\mathrm{T}+9$ at age 20 in Figure $6 \mathrm{a}$ are postponed by one year and moved diagonally along the cohort path so that they occur at age 21 at time $\mathrm{T}+10$ in situation $\mathrm{b}$. As a result, 9 years' worth of births are stretched out over 10 years, thus leading to a 10 percent decline in period fertility. By a similar argument it can be demonstrated that period fertility rises as the mean age declines in Figure $6 \mathrm{c}$. In this case, the number of births that occur between $\mathrm{T}$ and $\mathrm{T}+10$ equals the number between $\mathrm{T}$ and $\mathrm{T}+11$ in Figure 6a. In other words 11 years' worth of births are compressed into 10 years in moving from situation a to $\mathrm{c}$, which leads to a rise in fertility between $\mathrm{T}$ and $\mathrm{T}+10$. Bongaarts and Feeney (1998) present a fuller discussion of these effects.

Three key conclusions follow from this exercise and the earlier discussion of Figure 3:

1) Tempo distortions of period fertility occur during periods when the mean age at birth of a given order changes. It is not the absolute value of the mean age that matters but rather the fact that it is changing.

2) The size of the tempo distortion in a given TFR component depends on the annual change in the mean age of fertility at the corresponding birth order.

3) Tempo distortions have to be analyzed separately for each birth order. The sizes of tempo distortions can vary among orders because the rates of changes in their mean ages can differ. The trend in the mean age at childbearing for all births does not provide useful information about the overall size of the tempo distortions of the TFR except when fertility is constant.

Bongaarts and Feeney (1998) demonstrate that these three conclusions are valid not only for the highly simplified examples used in Figures 3 and 6, but also more generally when fertility is distributed over a range of ages. They also derive 
a simple equation for eliminating the tempo distortion from the observed TFR, as follows:

Let $\mathrm{m}_{\mathrm{o}}$ be the annual change in the mean age of the age-specific fertility schedule at birth order o during a given year or period. This changing mean causes a proportional distortion of the fertility rate at order o equal to $-\mathrm{m}_{\mathrm{o}}$. The relationship between the TFR with and without the distortion therefore is

$$
\operatorname{TFR}_{\mathrm{o}}=\mathrm{TFR}_{\mathrm{o}}{ }^{(}\left(1-\mathrm{m}_{\mathrm{o}}\right)
$$

where

$\mathrm{TFR}_{\mathrm{o}}=$ observed total fertility rate component for birth order o (with tempo effect)

$\mathrm{TFR}_{\mathrm{o}}=$ adjusted total fertility rate component for birth order o (without tempo effect).

Rearranging yields

$$
\mathrm{TFR}_{\mathrm{o}}=\mathrm{TFR}_{\mathrm{o}} /\left(1-\mathrm{m}_{\mathrm{o}}\right) \text {. }
$$

In other words, by dividing the observed total fertility rate component at any given birth order by $\left(1-\mathrm{m}_{\mathrm{o}}\right)$ one obtains the total fertility rate that would have been observed had there been no change in the timing of childbearing. The TFR' will be called the tempo-free or adjusted total fertility rate.

Summing results for different birth orders gives the overall tempo-free total fertility rate:

$$
\mathrm{TFR}^{\prime}=\Sigma \mathrm{TFR}^{\prime} .
$$

It is now a simple matter to determine the quantum and tempo components of the conventional total fertility rate: TFR' equals the quantum and TFR-TFR' equals the tempo part.

The results from these equations are, as expected, consistent with the findings in Figure 6. In Figure $6 \mathrm{~b}$ the annual increase of one-tenth of a year per year 
in the mean age at childbearing at order one $\left(\mathrm{m}_{1}=0.1\right)$ between $\mathrm{T}$ and $\mathrm{T}+10$ reduces fertility by 10 percent below its tempo-free level because TFR ${ }_{1}=$ TFR' $_{1}(1-0.1)$. Similarly, in Figure $6 \mathrm{~cm}_{1}$ equals -0.1 , inflating TFR 1 by 10 percent. Clearly, modest annual changes in the timing of childbearing at any birth order can produce substantial changes in observed fertility.

The approach taken here differs significantly from that used by Ryder. Although the distorting effects of changes in the tempo of cohort fertility on the TFR are seen as operating in the same manner, Ryder does not use order-specific analysis. Furthermore, Ryder assumes that changes in the tempo and quantum of cohort fertility drive changes in period fertility, while the above equation assumes that all fertility change is period driven. As discussed in more detail in Bongaarts and Feeney (1998) and Ní Bhrolcháin (1992), the latter assumption is supported by past research on the demographic determinants of fertility change.

\section{ESTIMATING TEMPO DISTORTIONS:}

\section{THE CASE OF TAIWAN}

The equations presented in the preceding section can be used to estimate the tempo distortions of observed TFR trends in populations, but their application requires accurate estimates of annual fertility rates by age and birth order. These data are available in few populations and they are especially rare in developing countries. Fortunately, Taiwan has maintained an accurate vital registration system and annually publishes a variety of fertility statistics in the Taiwan Demographic Factbook. This information permits a detailed analysis of the tempo effects in Taiwan from the late 1970s to the early 1990s.

The first step is the calculation of the TFR and its birth-order components as well as the mean ages at childbearing for each birth order, from the published annual age-order-specific fertility rates from 1977 to 1994. An examination of the trends in the mean ages at births of different orders as shown in Figure 7 confirms that tempo distortions are present during this period. The means for 
orders 1 to 4 plotted in this figure show a steady rise over time, implying a downward distortion of the TFR and its components. For example, the mean age at first birth rose from 23.9 years in 1980 to 25.3 years in 1990, an increase of 1.4 years over the decade or 0.14 per year (i.e. $\mathrm{m}_{1}=0.14$ ). As a consequence, the firstorder component of the TFR was, on average, 14 percent lower than it would have been without the timing distortion during the 1980s.

Application of equation (2) for all years and birth orders yields time series of adjusted tempo-free TFR components. Figure 8 plots the observed and tempofree TFR components for Taiwan, for the periods 1980-84 and 1985-89. The elimination of the tempo effects raises all components in both periods, with the largest absolute changes for the lowest orders. The distortions at birth orders 1,2, 3 , and 4 are estimated at $-13.3,-17.6,-14.6$, and -6.4 percent, respectively,

Figure 7 Average age at childbearing, by birth order: Taiwan, 1977-94

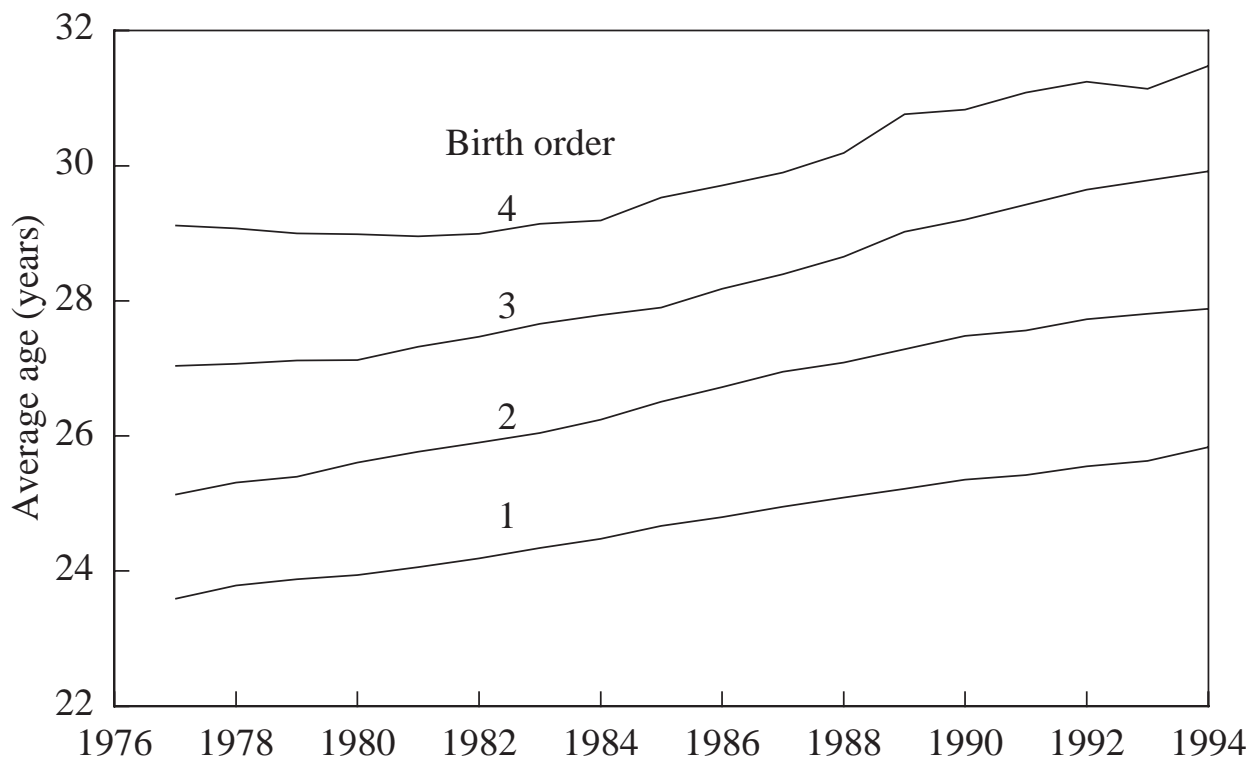

Source: Taiwan Demographic Factbook 1977-94. 
during the early 1980 s and at $-14.3,-20.2,-25.5$, and -29.5 percent during the late 1980s. Clearly, these effects are substantial.

Adding the observed and adjusted components for all birth orders yields the TFR and TFR' for each year from 1978 to 1993. These results are plotted in Figure 9 together with the corresponding estimates for birth order 1 . The TFR declined sharply from 2.68 in 1978 to 1.66 in 1986 before turning upward slightly to 1.76 by 1993 . The tempo-free TFR' exceeds the observed TFR throughout this period because the mean ages at births of all orders were rising, as shown in Figure 7. The total tempo effect amounts to about -10 percent in the late $1970 \mathrm{~s}$ and early 1990s, but it reached -19 percent in the late 1980s when the rate of change in the mean ages was most rapid. Although the observed TFR in Taiwan

Figure 8 Observed and tempo-free TFR components: Taiwan, 1980-84 and $1985-89$

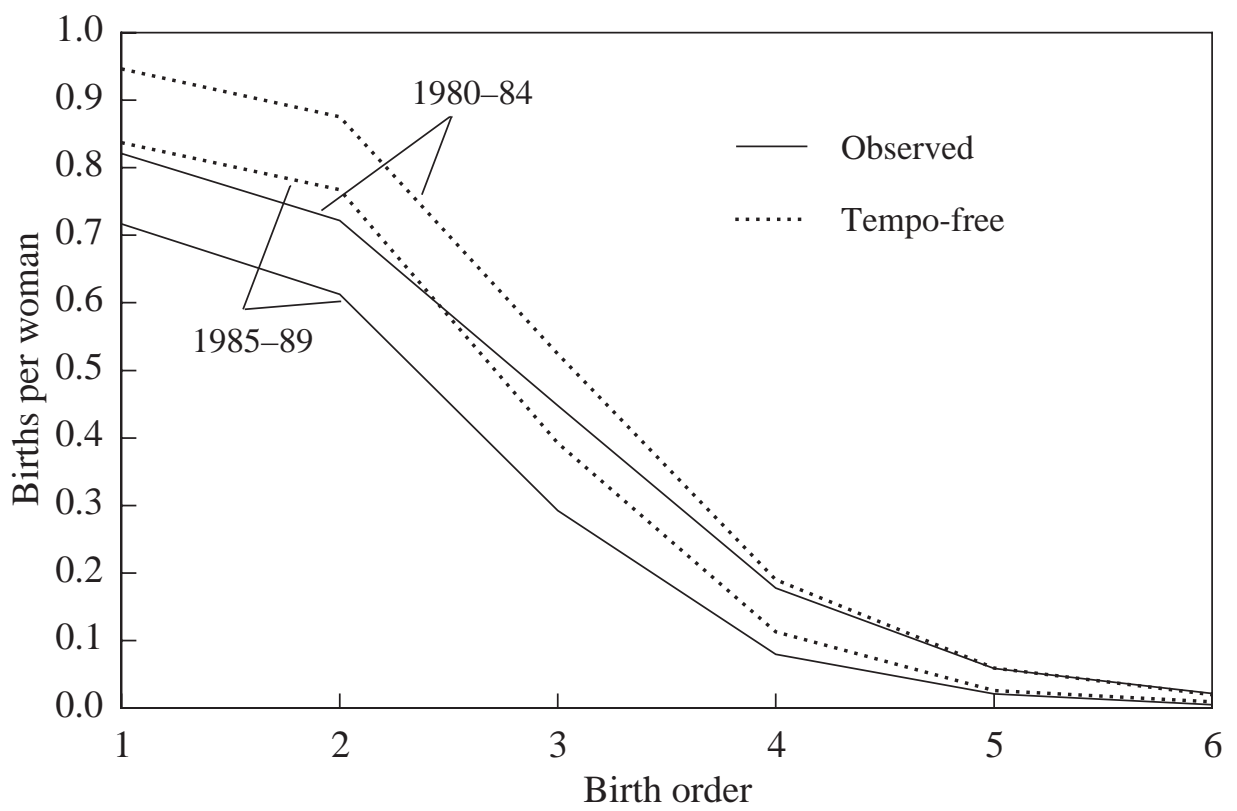

Source: Taiwan Demographic Factbook 1980-89. 
Figure 9 Observed and tempo-free TFR and TFR : Taiwan, 1978-93

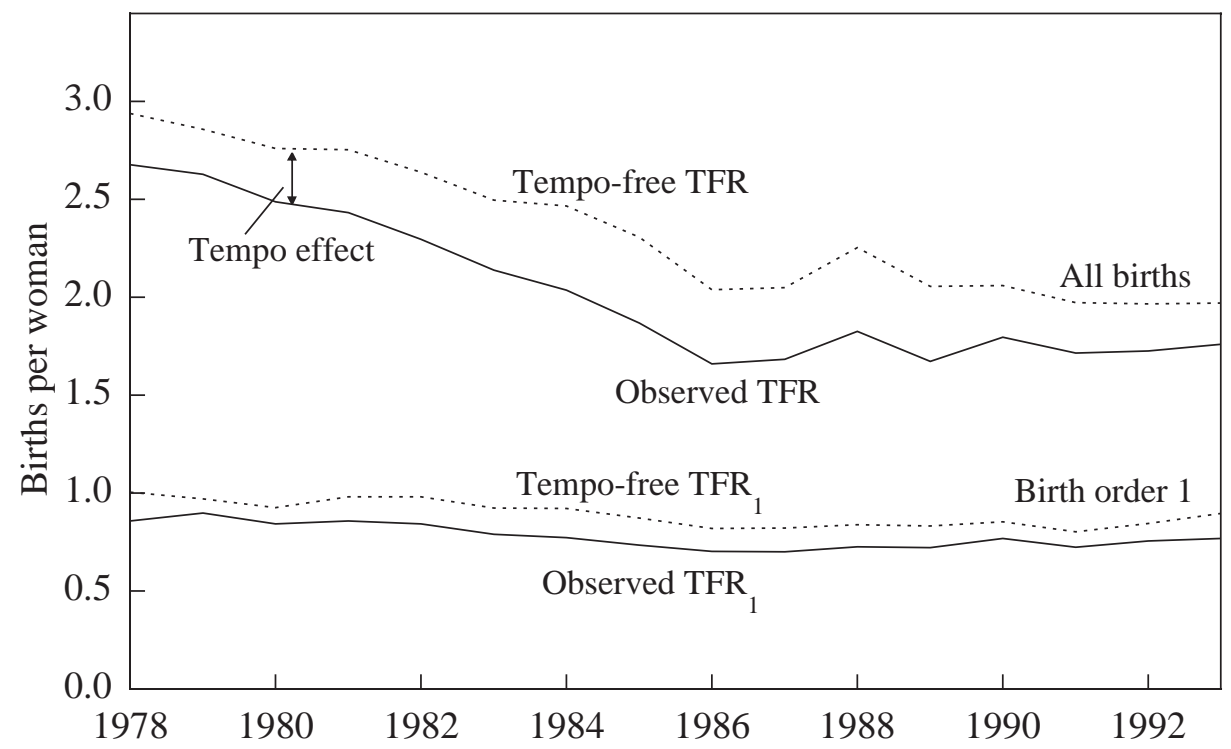

Sources: Taiwan Demographic Factbook 1991-93; Bongaarts and Feeney 1998.

has been well below replacement since 1986, the adjusted TFR' suggests that in the absence of tempo changes, reproduction would have been close to the replacement level.

\section{ESTIMATING TEMPO EFFECTS FROM SURVEY DATA: The Case of Colombia}

Most developing countries lack the detailed annual birth statistics available in Taiwan and in a number of industrialized countries. However, many developing countries have implemented one or more fertility surveys, such as the WFS or DHS, that permit the estimation of levels and trends in fertility and other indicators of reproductive behavior. Unfortunately, such surveys do not provide sufficient information to measure tempo effects accurately. This is also true in 
countries that have had multiple surveys. To illustrate the difficulties of analyzing tempo effects from surveys it is useful to take a closer look at one country. Colombia was selected for this exercise because data from four successive surveys are available: a WFS in 1976 and three DHS surveys, in 1986, 1990, and 1995. Moreover, an assessment of the quality of data collected in DHS surveys ranked Colombia's among the best (Rutstein and Bicego 1990; Arnold 1990).

The existence of tempo effects during Colombia's rapid fertility transition can be inferred with some confidence from trends in the mean ages at births of different orders. Figure 10 plots these means as estimated from each of the four surveys covering the period from the mid-1970s to the mid-1990s. (Average ages are derived from age-order-specific birth rates for the five-year periods preceding each survey.) The mean ages appear to have risen for most birth orders be-

Figure 10 Average age at childbearing, by birth order: Colombia, $1971-76$ to $1990-95$

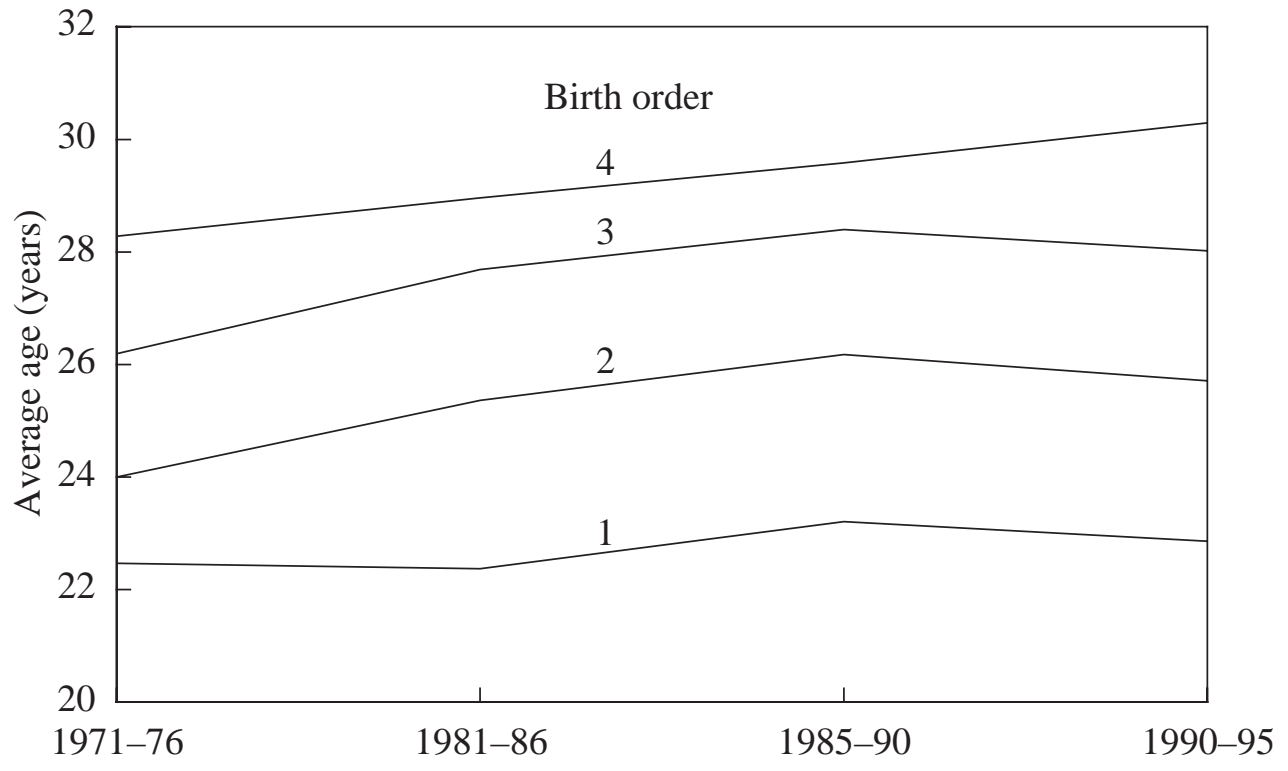

Source: Colombia WFS and DHS standard recode files. 
tween 1975 and 1990, but in the early 1990s this upward trend came to a halt. It is important to keep in mind that all estimates plotted in Figure 10 are subject to a variety of errors (sampling, reporting, etc.) and that errors of a few tenths of a year are likely to be common. This is unfortunate because highly accurate measurement of the means is necessary to obtain reliable estimates of tempo effects.

Another problem with information from fertility surveys is that it is difficult to estimate the change in the mean ages during the intervals in which fertility is measured. For example, to determine the tempo distortion in a particular fertility component based on births occurring during the five-year interval preceding a survey, one ideally would like to know the mean age of fertility at each order at the time of the survey as well as exactly five years before the survey. Subtracting these two estimates would give the change in the mean age over the five-year period and hence would provide the information necessary to calculate the tempo distortion in the TFR obtained from the survey data. Unfortunately such precise estimates are not available and it is therefore not possible to say with certainty whether Colombia experienced tempo distortions of the TFR components measured in any particular survey. However, it seems very likely that tempo distortions existed during most of the 1980s because the means at different orders rose fairly steadily from the 1970 s to the late 1980s (see Figure 10).

These increases in the mean ages at childbearing in Colombia during the 1980s should have produced tempo effects that depressed the order components of the TFR measured in the 1986 survey. The observed TFR components from the 1986 survey are plotted as the bottom line in Figure 11. The TFR ${ }_{1}$ is estimated at 0.77 first births per woman, substantially lower than one might expect: in no other developing country at a comparable stage in its transition have 23 percent of women remained childless. This finding suggests a tempo effect (or error). A crude estimate of the tempo distortion of these components can be obtained with the following simple three-step procedure: 1) subtract the mean ages at each birth 
Figure 11 Observed and tempo-free components of the TFR: Colombia, 1986

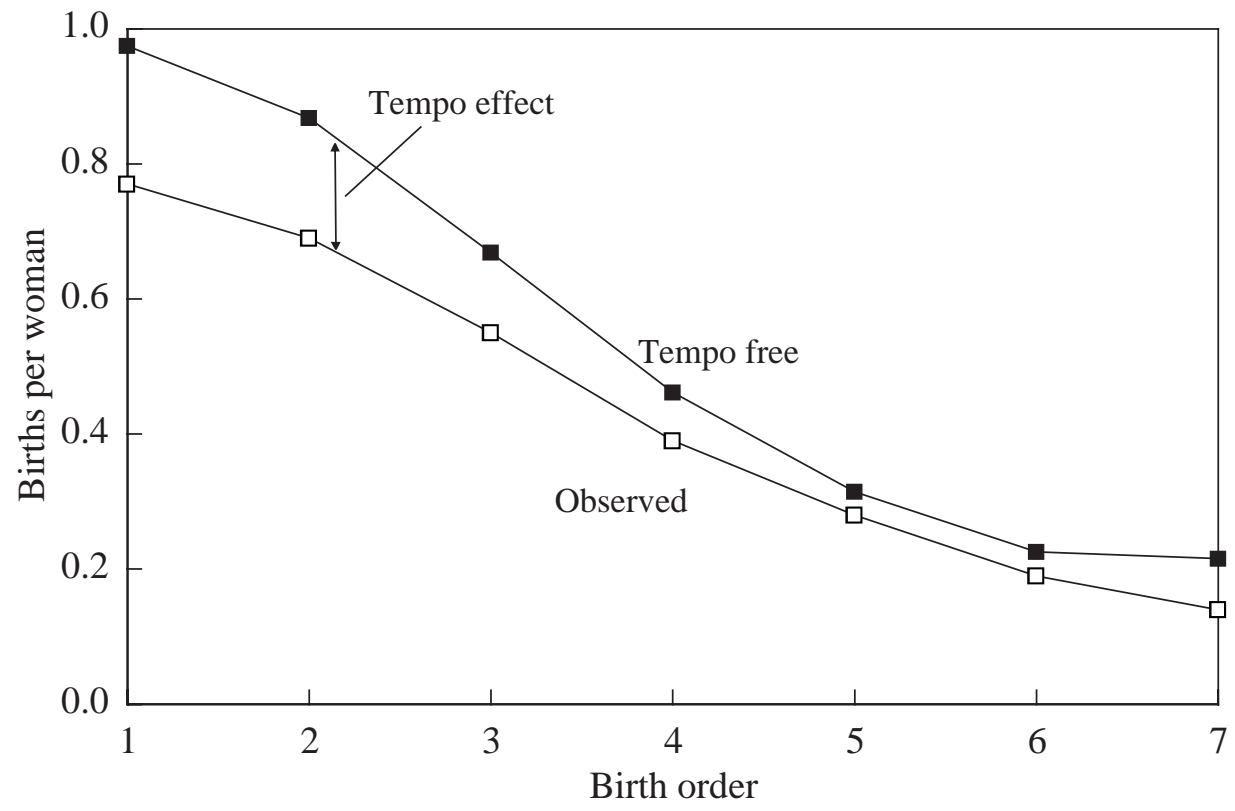

Source: Colombia DHS standard recode file.

order as measured in 1981-86 (from the 1986 survey) from those measured in 1985-90 (from the 1990 survey); 2) divide these differences by 4 to obtain the annual rates of change in the means; and 3) use equation (2) to obtain estimates of the tempo-free order components that would have been observed in the 1986 survey in the absence of tempo effects. The results of this exercise are plotted as the top line in Figure 11. The adjusted estimates are higher for all order components and give more plausible results at birth order 1 . The TFR', equals 0.97 , which implies that only 3 percent of women would remain childless given the propensity to reproduce in 1986. The adjusted tempo-free TFR' equals 4.07 births per woman instead of the 3.34 measured for the conventional TFR. The total tempo distortion therefore equals 0.7 births per woman. This estimate should be regarded as very approximate, because of a number of potential errors. 
An analysis of tempo effects can shed light on a puzzling development in Colombia's fertility transition. Throughout the 1970s and 1980s the TFR dropped steadily, reaching 2.9 births per woman in 1985-90 according to the 1990 DHS. However, instead of declining further in the early 1990s as most observers expected, fertility rose slightly to 3.0 births per woman according to the 1995 survey. Figure 12 plots these trends in the TFR as well as its birth-order components. An examination of the trend in the birth-order components reveals that the rise in the TFR between the two most recent surveys is entirely due to increases in the lowest births orders. Between the 1990 and 1995 surveys TFR rose from $_{1}$ 0.86 to $0.96, \mathrm{TFR}_{2}$ from 0.67 to 0.73 , and $\mathrm{TFR}_{3}$ from 0.46 to 0.51 . What can explain this unexpected trend? In theory it is possible that younger cohorts of

Figure 12 Total fertility rate and its birth-order components: Colombia, $1971-76$ to $1990-95$

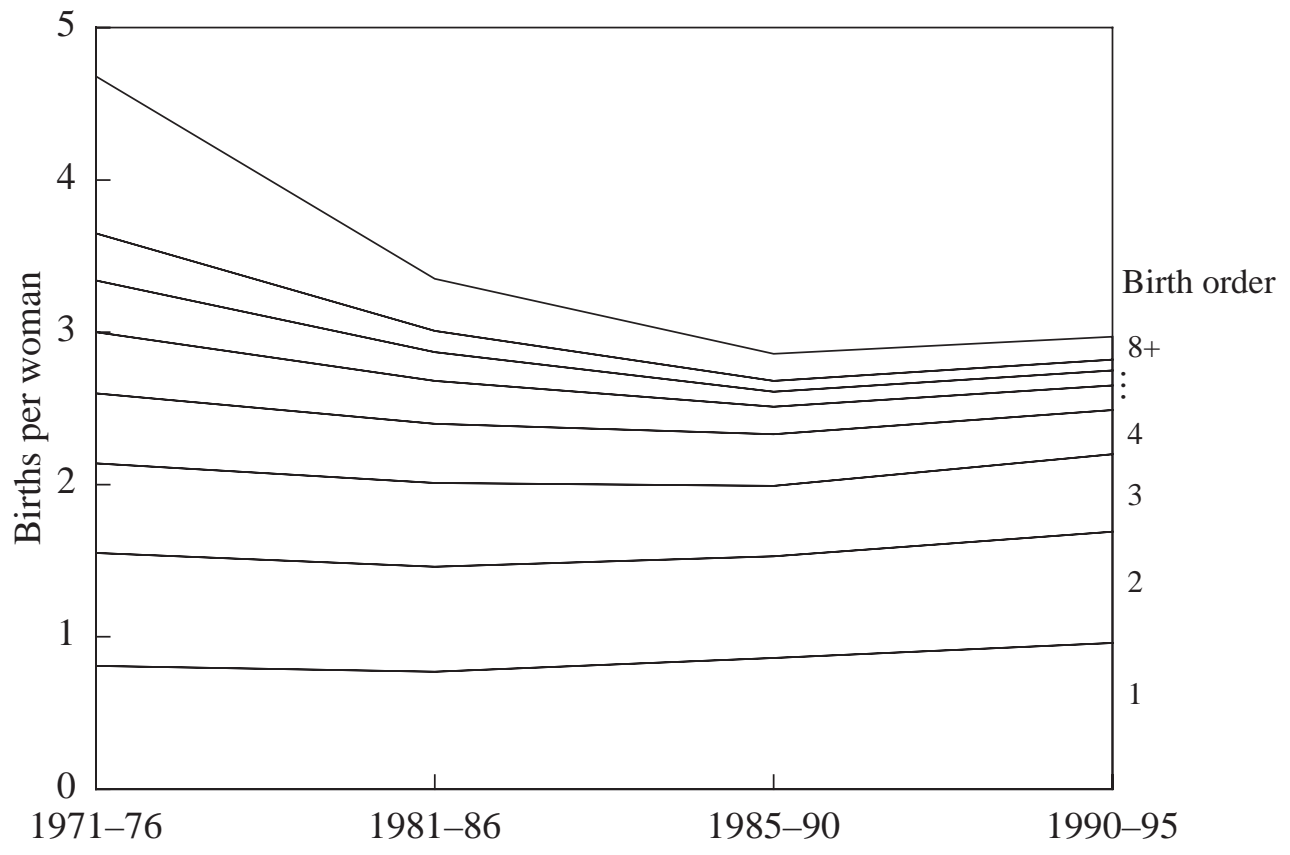

Source: Colombia DHS standard recode file. 
women are deciding to have more births of lower orders, or are having more unwanted births than was the case in the late 1980s, but this seems implausible.

Changes over time in the tempo effects provide a much more plausible explanation. As shown in Figure 10 the mean ages of births at different orders were rising in the 1970s and 1980s and this trend produced a fertility-depressing effect. But in the early 1990s this upward trend in the mean ages came to an end, thus removing the tempo distortions. On the basis of these trends in the mean ages, one would expect the disappearance of tempo effects in the early 1990s to result in increases in TFR components. This is indeed what is observed for birth orders 1,2, and 3. At higher orders the disappearance of tempo effects also puts upward pressure on fertility, but this is offset by a continuing decline in family sizes as one would expect in the normal course of the fertility transition. In other words, once the tempo effects are taken into account the trend in the TFR and its components in Colombia not only are no longer puzzling, they are actually what one would expect to find.

\section{EVIDENCE FOR TEMPO EFFECTS IN OTHER DEVELOPING COUNTRIES}

To document the existence of tempo effects in countries that lack vital registration systems one needs data from several successive fertility surveys. This is possible in a few countries, including Colombia, but most developing countries have only one or two fertility surveys. This makes it even more difficult to determine whether tempo effects exist, but the situation is not hopeless, as will be demonstrated next.

In countries with two surveys, the mean ages at births of different orders can be calculated from each survey, and the trends in these means then establish whether or not tempo changes have occurred. Table 1 presents the mean ages at births of orders 1 to 4 in the most recent DHS for 25 countries that had both a 
WFS and a DHS survey. Columns 5-8 present the estimated annual change in these mean ages over the period between the WFS and DHS. The last column in Table 1 gives the average annual change for the first four birth orders. According to this simple summary measure, the age at childbearing rose in the large majority of countries included in the table. In several countries (Ecuador, Indonesia, Morocco, Thailand, and Turkey) this change exceeded 0.1 years per year. Assuming no errors, these estimates imply substantial distortions of TFRs in the period between the surveys.

Unfortunately, this comparison of mean ages at births of different orders measured in two surveys does not permit identification of the precise years during which the tempo distortions occurred. If the change in the means occurred linearly between the surveys, then the tempo effects would have been constant over time (as in Figure 3b), but this is unlikely. In reality the tempo effects could have been larger earlier rather than later in the interval between the surveys, or vice versa. It is even possible that the effect was negative during some years and positive in others. The information available from two surveys can establish that there was a tempo distortion at some time between the two surveys, but it is not sufficient to pinpoint the size of the effects in different years.

The situation is even more difficult in populations where only one survey is available. However, two types of indirect evidence that the timing of births is changing can be derived from information collected in a single survey:

1) The size of the first-order component of the TFR. The TFR 1 is supposed to estimate the proportion of women who will have at least one birth during their reproductive years, given the propensity to reproduce at the time of the survey. Based on the reproductive histories of women who have completed their childbearing in different populations, one can expect this proportion to be above 0.9 in the large majority of developing countries (see Figure 4). The proportion is slightly lower in countries that have reached the end of the fertility transition, but even in contemporary developed countries where cohort fertility is near the replacement 


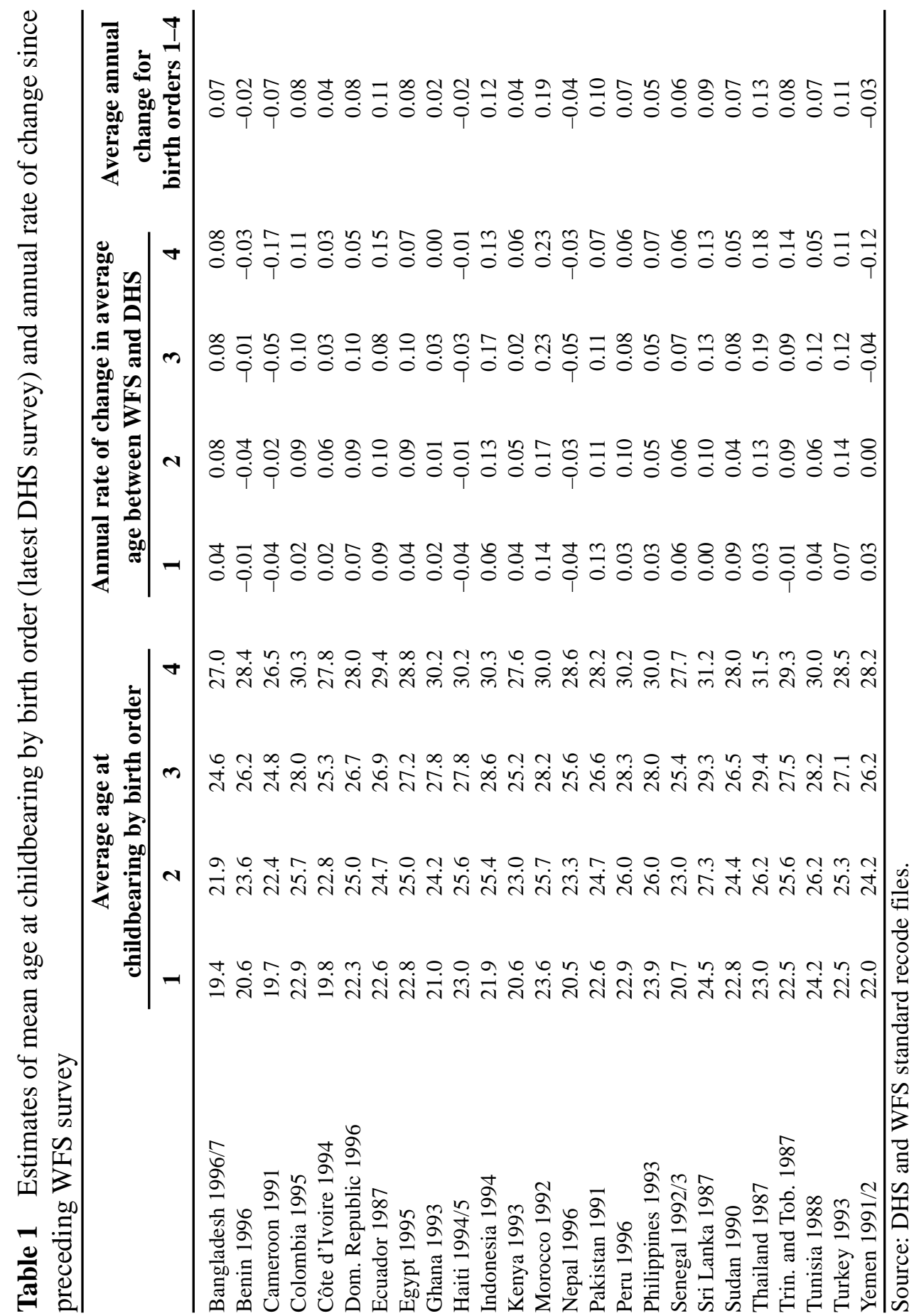


level it is typically still above 0.85 , because few women remain childless (Prioux 1993). These findings suggests that if $\mathrm{TFR}_{1}$ in a developing country is below about 0.85 or certainly below 0.80 , then a tempo distortion (or a measurement error) is present. Table 2 presents estimates of TFR from the most recent survey in 48 developing countries. The $\mathrm{TFR}_{1}$ ranges from a high of 0.98 births per woman in Namibia to 0.60 in Sudan. Since errors are likely, definite conclusions cannot be drawn, but in one-third of these countries the $\mathrm{TFR}_{1}$ is less than 0.8 , indicating tempo distortions.

2) Trend in median age at first birth. Estimates of the median ages at first births for successive age groups of women are routinely included in the DHS country reports. Table 2 shows these medians for women aged 20-24, 25-29, and 30-34 at the time of the survey. For more than half of these countries an estimate is lacking for age group 20-24 because the median was higher than age 20. In the large majority of countries the median age at first birth has risen over time, which - assuming accurate measurement_ implies a comparable rise in the average age at first birth. A strong upward trend at a rate greater than 0.1 years per year is found in 11 of these countries.

As one would expect, these two indicators of timing changes are correlated. Countries with a low $\mathrm{TFR}_{1}$ also tend to have experienced large increases in the median age at first birth and vice versa. The correlation coefficient between TFR $_{1}$ and the rate of change in the median age at first birth is a statistically significant 0.63 . The correlation is less than perfect in part because increases in these medians occurred mostly before the periods when the $\mathrm{TFR}_{1}$ is measured. The strongest indications of tempo effects are found in the following ten countries in which $\mathrm{TFR}_{1}$ was below 0.8 and the median age at first birth rose at a rate higher than 0.1 year per year: Bangladesh, Comoros, Egypt, Indonesia, Mexico, Morocco, Sri Lanka, Sudan, Tunisia, and Turkey.

A shortcoming of both approaches for identifying tempo effects from single surveys is that they cannot be applied to higher-order births. At orders above 1 it 
Table 2 Estimates of first-order component of the total fertility rate $\left(\mathrm{TFR}_{1}\right)$ and median ages at first birth by age at survey for 48 populations

\begin{tabular}{|c|c|c|c|c|c|}
\hline & \multirow[b]{2}{*}{ TFR $_{1}$} & \multicolumn{3}{|c|}{ Median age at first birth } & \multirow{2}{*}{$\begin{array}{l}\text { Annual change } \\
\text { in median age }\end{array}$} \\
\hline & & $20-24$ & $25-29$ & $30-34$ & \\
\hline Bangladesh 1996/7 & $0.67+$ & 18.4 & 17.4 & 17.2 & $0.12 *$ \\
\hline Benin 1996 & 0.90 & & 19.8 & 19.5 & 0.06 \\
\hline Bolivia 1994 & 0.92 & & 21.1 & 20.7 & 0.08 \\
\hline Botswana 1988 & 0.89 & 19.7 & 19.2 & 19.3 & 0.04 \\
\hline Brazil 1996 & 0.85 & & 22.2 & 22.2 & 0.00 \\
\hline Burkina Faso 1992/3 & 0.91 & 19.1 & 19.0 & 18.8 & 0.03 \\
\hline Burundi 1987 & 0.81 & & 20.9 & 21.1 & -0.04 \\
\hline Cameroon 1991 & $0.77+$ & 18.4 & 18.6 & 18.6 & -0.02 \\
\hline Centr. Afr. Rep. 1995 & 0.87 & 18.9 & 19.4 & 19.4 & -0.05 \\
\hline Colombia 1995 & 0.96 & & 22.4 & 22.2 & 0.04 \\
\hline Comoros 1996 & $0.65+$ & & 22.4 & 20.9 & $0.30^{*}$ \\
\hline Côte d'Ivoire 1994 & $0.77+$ & 18.6 & 18.6 & 18.7 & -0.01 \\
\hline Dom. Republic 1996 & 0.91 & & 21.2 & 21.4 & -0.04 \\
\hline Ecuador 1987 & 0.85 & & 20.7 & 21.0 & -0.06 \\
\hline Egypt 1995 & $0.78+$ & & 22.0 & 21.4 & $0.12^{*}$ \\
\hline Ghana 1993 & 0.97 & & 20.3 & 20.0 & 0.06 \\
\hline Guatemala 1995 & 0.86 & & 20.2 & 19.8 & 0.08 \\
\hline Haiti 1994/5 & 0.86 & & 21.9 & 22.0 & -0.02 \\
\hline Indonesia 1994 & $0.75+$ & & 21.0 & 20.1 & $0.18^{*}$ \\
\hline Kenya 1993 & 0.81 & 19.8 & 19.3 & 19.0 & 0.08 \\
\hline Liberia 1986 & 0.95 & 18.5 & 19.0 & 19.4 & -0.09 \\
\hline Madagascar 1992 & 0.90 & 19.7 & 19.6 & 18.9 & 0.08 \\
\hline Malawi 1992 & 0.86 & 18.9 & 18.7 & 18.3 & 0.06 \\
\hline Mali 1996 & 0.94 & 18.3 & 18.6 & 18.5 & -0.02 \\
\hline Mexico 1987 & $0.78+$ & 22.5 & 21.2 & 20.5 & $0.20^{*}$ \\
\hline Morocco 1992 & $0.63+$ & & 24.9 & 22.2 & $0.54 *$ \\
\hline Namibia 1992 & 0.98 & & 21.2 & 20.5 & $0.14^{*}$ \\
\hline Nepal 1996 & 0.96 & 19.9 & 19.4 & 19.7 & 0.02 \\
\hline Niger 1992 & 0.81 & 17.7 & 17.8 & 17.9 & -0.02 \\
\hline Nigeria 1990 & 0.84 & 19.7 & 19.6 & 19.1 & 0.06 \\
\hline Pakistan 1991 & $0.66+$ & & 21.0 & 20.9 & 0.02 \\
\hline Paraguay 1990 & 0.97 & & 21.5 & 21.6 & -0.02 \\
\hline Peru 1996 & 0.88 & & 21.9 & 21.5 & 0.08 \\
\hline Philippines 1993 & 0.81 & & 23.1 & 22.9 & 0.04 \\
\hline Rwanda 1992 & 0.89 & & 22.0 & 21.7 & 0.06 \\
\hline Senegal 1992/3 & $0.78+$ & 19.8 & 19.3 & 18.8 & 0.10 \\
\hline Sri Lanka 1987 & $0.76+$ & & 24.7 & 24.1 & $0.12 *$ \\
\hline Sudan 1990 & $0.60+$ & & 22.8 & 20.8 & $0.40^{*}$ \\
\hline Tanzania 1996 & 0.89 & 19.8 & 19.4 & 19.2 & 0.06 \\
\hline Thailand 1987 & $0.73+$ & 23.0 & 22.7 & 22.3 & 0.07 \\
\hline Togo 1988 & 0.84 & 19.5 & 19.2 & 18.8 & 0.07 \\
\hline Trin. and Tob. 1987 & 0.81 & & 22.2 & 21.9 & 0.06 \\
\hline Tunisia 1988 & $0.72+$ & & 24.5 & 23.2 & $0.26^{*}$ \\
\hline Turkey 1993 & $0.74+$ & & 21.8 & 20.7 & $0.22 *$ \\
\hline Uganda 1995 & 0.96 & 18.7 & 18.9 & 18.4 & 0.03 \\
\hline Yemen 1991/2 & $0.66+$ & & 19.9 & 19.5 & 0.08 \\
\hline Zambia 1996/7 & 0.88 & 19.0 & 19.0 & 18.7 & 0.03 \\
\hline Zimbabwe 1994 & 0.85 & & 19.7 & 19.3 & 0.08 \\
\hline
\end{tabular}

+ indicates values below $0.8 \quad *$ indicates values above 0.1

Source: DHS and WFS standard recode files. 
becomes difficult to distinguish between true quantum effects and tempo distortions. Nevertheless, the evidence for a tempo effect at birth order 1 in many developing countries strongly suggests that similar or possibly even larger effects are also present at higher birth orders in these countries.

\section{DISCUSSION AND CONCLUSION}

The preceding analysis indicates that trends in the total fertility rate of many developing countries are likely to be distorted by tempo effects. Although distortions can in theory be either positive or negative, the general trend toward later ages at childbearing in many developing countries implies that these effects are usually negative, that is, observed fertility is lower than it would have been without the tempo change. This effect is most clearly documented in Taiwan, where accurate birth statistics from a vital registration system make it possible to estimate the annual quantum and tempo components of the TFR. These estimates indicate that rising ages at childbearing depressed fertility by about 19 percent in 1985-89. In the absence of tempo effects Taiwan's TFR would have been close to the replacement level, instead of the observed level of 1.74 births per woman during the late 1980s.

In the absence of vital registration data the measurement of tempo effects becomes difficult. An examination of trends in the mean ages at births of different orders between surveys or of trends in the median ages at first birth can determine whether such effects have existed, but it is virtually impossible to measure accurately the size of the effect at a particular point in time. Countries with multiple successive surveys are in the best position to determine their situation, as was demonstrated for Colombia. In the mid-1980s Colombia's TFR was depressed by an estimated 0.7 births per woman. Whether distortions of this magnitude exist elsewhere is not easily determined from the available evidence, but judging from two different indicators substantial distortions could well exist in Bangla- 
desh, Comoros, Egypt, Indonesia, Mexico, Morocco, Sri Lanka, Sudan, Tunisia, and Turkey at the time of their most recent surveys.

The implications of tempo effects for observed trends in fertility over the course of the transition depend not only on the size of the effect, but also on its duration. To illustrate, Figure 13 presents three possible scenarios with effects of different durations. Each plot compares the observed TFR with the TFR that would have been observed without tempo effects (i.e., the quantum); the latter is assumed to be the same in all three scenarios. The tempo effects (shaded areas) are assumed to be negative. Figure 13a depicts the situation in which the tempo effect is of relatively short duration, so that it peaks in mid-transition and disappears before the transition ends. In this case observed fertility reaches a temporary plateau, at the time when the declining tempo effect offsets any ongoing declines in the quantum of fertility. This case is not unlike that of Colombia in the early 1990s, as discussed earlier. In the second scenario in Figure 13b the tempo effect is of intermediate duration and its end coincides with the end of the transition. In this case no unusual patterns are observed, but the tempo effect has caused the transition to occur faster than it would have otherwise. Finally, in Figure 13c the tempo effect is assumed to be of the longest duration, continuing past the end of the transition. In this case, observed fertility drops below replacement at the end of the transition while the quantum component levels off at a higher level (i.e., at replacement level). The United States in the 1970s and 1980s exemplifies such a scenario (see Bongaarts and Feeney 1998). Once the timing effect disappears, observed fertility rises back to the tempo-free level, as indeed happened in the US in the late 1980s. Taiwan appears to be following the same pattern, but it is unclear when the tempo effect will end.

Because the size, timing, duration, and even the direction of the tempo effects vary among populations and because these variables cannot easily be measured, it is not possible to say how large the effect is at present in most contempo- 
Figure 13 Hypothetical transitions in the total fertility rate and its tempo components with tempo effects of different durations
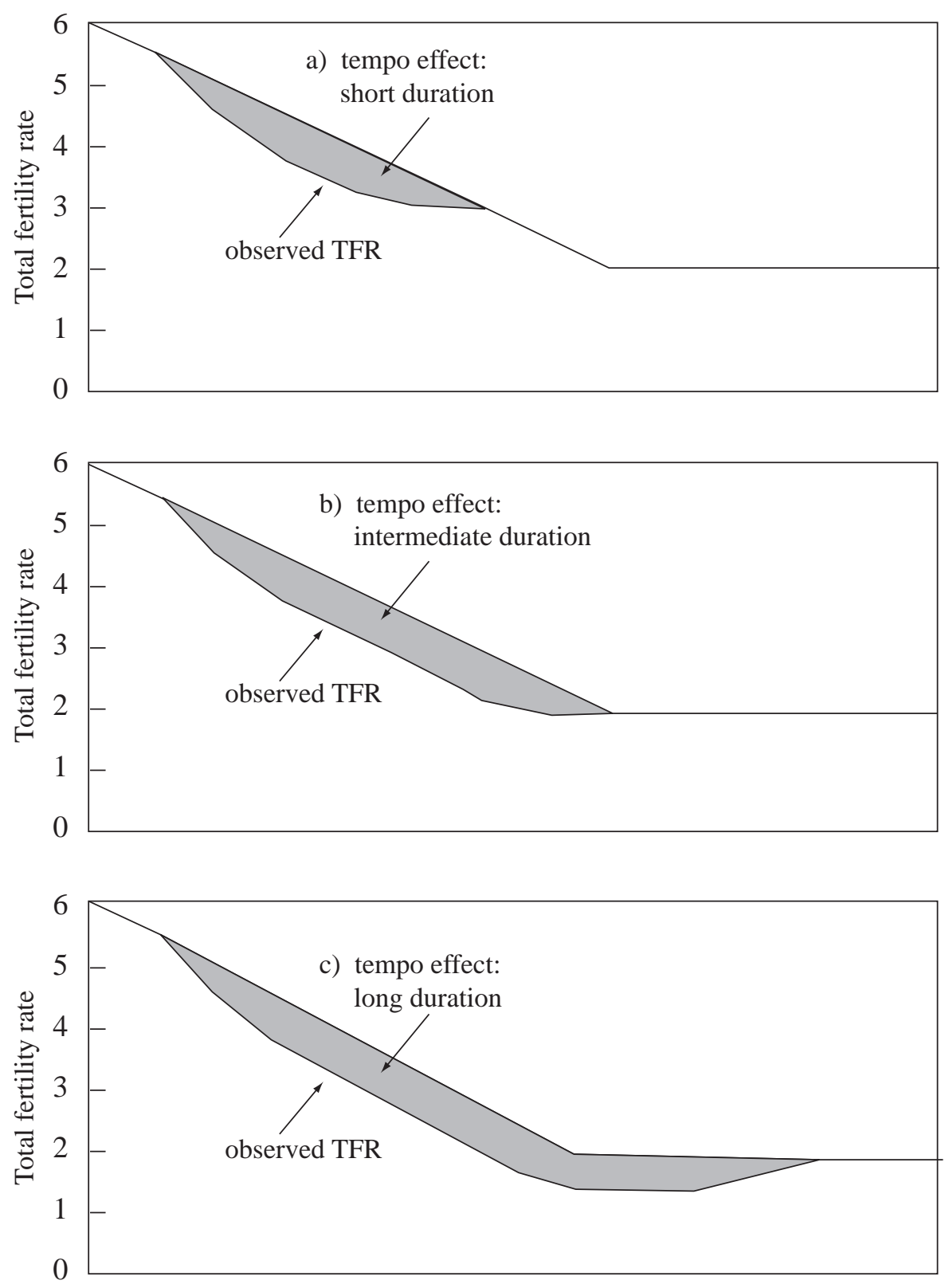
rary populations or whether it will change over time. Nevertheless, it is likely that a number of developing countries are now experiencing tempo distortions. When changes in the timing of childbearing that cause these distortions end, as they eventually must, upward pressure will be exerted on fertility. If this happens in a society that is still in transition, then a fertility transition that now appears to be moving smoothly and rapidly could be interrupted at least temporarily, as was the case in Colombia in the early 1990s. Fertility has stalled temporarily in other countries as well (e.g., in Costa Rica in the 1970s), and it would not be surprising if this happens elsewhere in countries in mid-transition. Countries where substantial tempo effects are present today are the most vulnerable to stalls in their fertility transitions.

Fertility reductions caused by tempo effects lead to real declines in birth rates and hence in population growth. Countries in which birth or population growth rates are higher than desirable can consider taking appropriate actions that encourage women to delay marriage and the onset of childbearing in order to produce negative tempo effects. There is little practical program experience to draw on, but the promotion of girls' education to the secondary level and their inclusion in community income-generating activities offer young women opportunities for their own development, and these women are likely to delay the onset of the first and subsequent births. These measures therefore directly benefit women, and the resulting tempo effects accelerate the fertility transition.

\section{Note}

1 Once the components CTFR are known, other order-specific measures can be calculated. For example, the parity progression ratio at parity o equals $\mathrm{CTFR}_{\mathrm{O}+1} /$ $\mathrm{CTFR}_{\mathrm{o}}$ and the proportion of the cohort that has exactly o births equals $\mathrm{CTFR}_{\mathrm{o}+1}-$ CTFR $_{\mathrm{o}}$ (Lutz 1989). For a discussion of the estimation of period parity progression ratios see Feeney and Yu (1987) and Ní Bhrolcháin (1987). 


\section{References}

Arnold, Fred. 1990. "Assessment of the quality of birth history data in the Demographic and Health Surveys," in An Assessment of DHS-I Data Quality. DHS Methodological Reports No. 1, Columbia, Maryland: Institute for Resource Development/Macro Systems, Inc.

Blanc, Ann K. and Naomi Rutenberg. 1990. "Assessment of the quality of data on age at first sexual intercourse, age at first marriage, and age at first birth in the Demographic and Health Surveys," in An Assessment of DHS-I Data Quality. DHS Methodological Reports No.1, Columbia, Maryland: Institute for Resource Development/Macro Systems, Inc.

Bongaarts, John. 1998. "Fertility and reproductive preferences in post-transitional societies," Policy Research Division Working Paper No. 114, New York: Population Council.

Bongaarts, John and Griffith Feeney. 1998. "On the quantum and tempo of fertility," Population and Development Review 24: 271-291.

Feeney, Griffith and Jingyuan Yu. 1987. "Period parity progression measures of fertility in China," Population Studies 41: 77-102.

Hobcraft, John. 1996. "Fertility in England and Wales: A fifty-year perspective," Population Studies 50: 485-524.

Lutz, Wolfgang. 1989. Distributional Aspects of Human Fertility. London: Academic Press.

Ní Bhrolcháin, Máire. 1987. "Period parity progression ratios and birth intervals in England and Wales, 1941-1971: A synthetic life table analysis," Рориlation Studies 41: 103-125.

. 1992. "Period paramount? A critique of the cohort approach to fertility," Population and Development Review 18: 599-629.

Pressat, Roland. 1985. The Dictionary of Demography. Edited by Christopher Wilson. Oxford: Basil Blackwell. 
Prioux, France. 1993. "L'infécondité en Europe," in Alain Blum and Jean-Louis Rallu (eds.), European Population, II. Demographic Dynamics. Paris: John Libbey.

Republic of China. 1990. Statistical Yearbook of the Republic of China 1990. Directorate-General of Budget, Accounting and Statistics, Executive Yuan, Republic of China.

. 1991. Statistical Yearbook of the Republic of China 1991. Directorate-General of Budget, Accounting and Statistics, Executive Yuan, Republic of China.

Ryder, Norman B. 1964. "The process of demographic translation," Demography 1: 74-82.

. 1980. "Components of temporal variations in American fertility," in R.W. Hiorns (ed.), Demographic Patterns in Developed Societies. London: Taylor \& Francis, pp. 15-54.

. 1983. "Cohort and period measures of changing fertility," in Rodolfo A. Bulatao and Ronald D. Lee (eds.), Determinants of Fertility in Developing Countries. New York: Academic Press, Vol. 2, pp. 737-756.

Rutstein, Shea Oscar and George T. Bicego. 1990. "Assessment of the quality of data used to ascertain eligibility and age in the Demographic and Health Surveys," in An Assessment of DHS-I Data Quality. DHS Methodological Reports No.1, Columbia, Maryland: Institute for Resource Development/ Macro Systems, Inc.

Singh, Susheela and Renee Samara. 1996. "Early marriage among women in developing countries," International Family Planning Perspectives 22: 148-157, 175.

United Nations. 1996. World Population Prospects: The 1996 Revision. Annex I: Demographic Indicators. New York: United Nations Department for Economic and Social Information and Policy Analysis, Population Division.

World Bank. 1998. Unpublished input data files for population projections of the World Bank. 


\title{
POLICY RESEARCH DIVISION WORKING PAPERS
}

\author{
Recent Back Issues
}

\section{7}

93 James F. Phillips, Fred N. Binka, Martin Adjuik, Alex Nazzar, and Kubaze Frank Adazu, "The determinants of contraceptive innovation: A case-control study of family planning acceptance in a traditional African society."

94 John Bongaarts and Sajeda Amin, "Prospects for fertility decline and implications for population growth in South Asia."

95 Barbara S. Mensch and Cynthia B. Lloyd, "Gender differences in the schooling experiences of adolescents in low-income countries: The case of Kenya."

96 Martin Brockerhoff and Ellen Brennan, "The poverty of cities in the developing world."

97 Carol E. Kaufman, "Reproductive control in South Africa."

98 John Bongaarts, "Trends in unwanted childbearing in the developing world."

99 Mary Arends-Kuenning, "How do family planning workers' visits affect wom- en's contraceptive behavior in Bangladesh?"

100 Mark R. Montgomery and Cynthia B. Lloyd, "Excess fertility, unintended births, and children's schooling."

101 Mary Arends-Kuenning, "The equity and efficiency of doorstep delivery of contraceptives in Bangladesh."

102 Sajeda Amin, Ian Diamond, Ruchira T. Naved, and Margaret Newby, "Transition to adulthood of female factory workers: Some evidence from Bangladesh."

*103 Margaret E. Greene and Ann E. Biddlecom, "Absent and problematic men: Demographic accounts of male reproductive roles."

104 Michael P. Todaro, "Urbanization, unemployment, and migration in Africa: Theory and policy."

105 Geoffrey McNicoll, "Population and poverty: A review and restatement."

* No longer available 
106 Sajeda Amin and Gilda Sedgh, "Incentive schemes for school attendance in rural Bangladesh."

107 Martin Brockerhoff and Paul Hewett, "Ethnicity and child mortality in subSaharan Africa."

108 Ann E. Biddlecom and Bolaji M. Fapohunda, "Covert contraceptive use: Prevalence, motivations, and consequences."

109 John Bongaarts and Griffith Feeney, "On the quantum and tempo of fertility."

110 Barbara S. Mensch, Daniel Bagah, Wesley H. Clark, and Fred Binka, "The changing social environment for adolescents in the Kassena-Nankana District of northern Ghana: Implications for reproductive behavior."

111 Martin Brockerhoff and Ann Biddlecom, "Migration, sexual behavior, and HIV diffusion in Kenya."

112 Zeba A. Sathar and John B. Casterline, "The onset of fertility transition in Pakistan."

113 Geoffrey McNicoll, "Government and fertility in transitional and post-transitional societies."
114 John Bongaarts, "Fertility and reproductive preferences in post-transitional societies."

115 Fiona Steele, Sajeda Amin, and Ruchira T. Naved, "The impact of an integrated micro-credit program on women's empowerment and fertility behavior in rural Bangladesh.”

116 Cynthia B. Lloyd, Barbara S. Mensch, and Wesley H. Clark, "The effects of primary school quality on the educational participation and attainment of Kenyan girls and boys."

117 Sajeda Amin and Cynthia B. Lloyd, "Women's lives and rapid fertility decline: Some lessons from Bangladesh and Egypt."

118 James F. Phillips and Mian Bazle Hossain, "The impact of family planning household service delivery on women's status in Bangladesh."

119 Mark R. Montgomery and John B. Casterline, "Social networks and the diffusion of fertility control."

120 John Bongaarts, "The fertility impact of changes in the timing of childbearing in the developing world." 